Brit. J. prev. soc. Med. (1961), 15, 189

\title{
STILLBIRTH IN THE CITY OF BOMBAY
}

\author{
BY \\ SAROJ S. JHA \\ Department of Preventive and Social Medicine, Topiwala National Medical College, Bombay, India
}

Stillbirth is to be encountered in every human population and its causes are the same everywhere, although the magnitude of the contribution of specific causes differs in time and place. In countries where the medical and social services available to the expectant mother have recently undergone a rapid development and where records relating to stillbirth have been maintained for many years, it has been observed that as the standard of living has risen the stillbirth rate has fallen, and it is reasonable to assume that in the future the rate will fall in other countries when the standard of living and of medical care has improved.

The stillbirth ratio in the Indian population as a whole cannot be given. In India, as also for example in Egypt, the figures given in the "Demographic Yearbook of the United Nations" for 1957 (Table I) relate to certain selected registration areas only.

TABLE I

RATIO OF STILLBIRTHS TO LIVE BIRTHS PER 1,000 IN SELECTED COUNTRIES*

\begin{tabular}{c|c|c}
\hline Country & Ratio & Year \\
\hline Ceylon & $47 \cdot 0$ & 1957 \\
Burma & $40 \cdot 0$ & 1955 \\
Chile & $32 \cdot 3$ & 1954 \\
Scotland & $24 \cdot 4$ & 1956 \\
England and Wales & $23 \cdot 5$ & 1956 \\
Austria & $18 \cdot 0$ & 1956 \\
Dennark & $17 \cdot 8$ & 1956 \\
Holland & $17 \cdot 2$ & 1956 \\
France & $17 \cdot 2$ & 1956 \\
Sweden & $16 \cdot 4$ & 1956 \\
Mexico & $15 \cdot 7$ & 1955 \\
Switzerland & $13 \cdot 7$ & 1956 \\
U.S.A. & $13 \cdot 5$ & 1955 \\
Pakistan & $13 \cdot 2$ & 1951 \\
India & $8 \cdot 6$ & 1954 \\
Egypt & 6.0 & 1954 \\
\hline
\end{tabular}

* Demographic Yearbook of the United Nations for the year 1957 Ninth issue).

Though the ratio quoted for India in Table $I$ is certainly very wide of the mark, the decrease in successive years suggests that the ratio of stillbirths to live births is gradually falling (Table II).

TABLE II

RATIO OF STILLBIRTHS TO LIVE BIRTHS PER 1,000 IN INDIA, IN 1948-54*

\begin{tabular}{c|c}
\hline Year & Ratio \\
\hline 1948 & 14.4 \\
1949 & 15.4 \\
1950 & 13.1 \\
1951 & 12.6 \\
1952 & 12.4 \\
1953 & 11.2 \\
1954 & 8.6 \\
\hline
\end{tabular}

- Demographic Yearbook of the United Nations for the year 1957 (Ninth issue).

An indication of the trends in the stillbirth rate in India as a whole and of the factors influencing changes therein has been sought in the records for the year 1957 in the Health Department of the Bombay Municipal Corporation. The birth registers give the number of live births as 84,910 and that of stillbirths as 2,378 , a stillbirth rate of $27 \cdot 2$ per 1,000 total births (the same definition of stillbirth being accepted in India as in the United Kingdom).

Although it is the practice to register a stillbirth both as a birth and as a death, in many instances only the death was registered. This was particularly so in the case of infants born at home, where the death certificate was required for the purposes of cremation, etc. The number of stillbirths given in the "Annual Report of the Executive Health Officer" for 1957 is 2,861, a stillbirth rate of 32.6 per thousand total births. It is these stillbirths which are registered only as deaths that account for the discrepancy between this figure and that already given ( 27.2 per thousand), an underestimation of about 5 per thousand.

It was hoped to obtain from the records information regarding maternal age, parity, the district 
within the City where the family lived, the place of confinement (home or hospital), the father's occupation and religion, and the sex of the stillborn infant. Many of these particulars were too scanty and uncertain to be of any value; for example, any attempt to construct a social gradient was foiled by the frequent use of such terms as "service" or "business" for the father's occupation. In the end only maternal age, parity, and sex of infant were considered. The actual cause of the stillbirth (for example, disease in the mother, foetal defect, disorder of placenta or cord, etc.) was not stated in the records. Where only the death was registered the maternal age and parity were not available.

\section{Influence of Maternal Age and Parity}

Table III shows the stillbirth rate per 1,000 total births in Bombay in 1957 by maternal age. The rate is relatively high in the youngest age group (15 to 19 years), falls during the next decade, but rises again after age 29 and goes up steeply after age 39 (Fig. 1).

TABLE III

STILLBIRTH RATES PER 1,000 TOTAL BIRTHS, BY MATERNAL AGE, BOMBAY, 1957

\begin{tabular}{c|c}
\hline Maternal Age (yrs) & Rate \\
\hline Under 20 & $30 \cdot 8$ \\
$20-$ & $24 \cdot 4$ \\
$25-$ & $24 \cdot 6$ \\
$30-$ & $31 \cdot 9$ \\
$35-$ & $34 \cdot 5$ \\
$40+$ & $45 \cdot 6$ \\
\hline All Ages & $27 \cdot 2$ \\
\hline
\end{tabular}

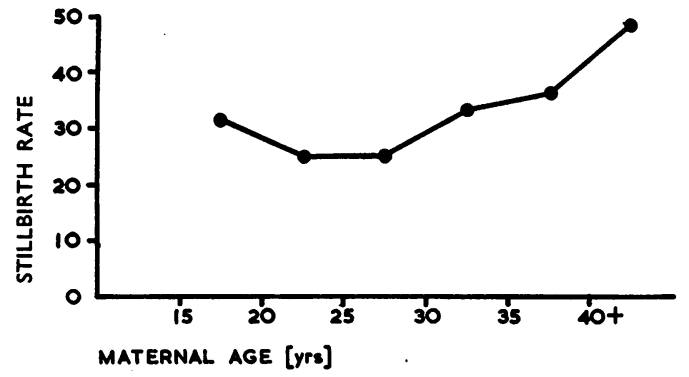

FIG. 1.-Stillbirth rate, by maternal age.

The level for the 30-34 age group is only slightly higher than that for the 15-19 age group, but at 40 years and over it is nearly one and a half times as high. The initial high level can be explained on the grounds of "reproductive immaturity" in the young mother and the secondary rise on the grounds of "reproductive inefficiency" with increasing age.

Table IV shows the stillbirth rate by parity. The rate is relatively high among first births; it then falls sharply but rises again after the fourth confinement and continues to rise with every successive confinement. Although the stillbirth rate starts to rise after the fourth child, it does not exceed the rate for the first until para 7 is reached. After the eighth it rises steeply so that for the tenth it is nearly double the rate for the first. (Fig. 2).

TABLE IV

STILLBIRTH RATES PER 1,000 TOTAL BIRTHS, BY PARITY, BOMBAY, 1957

\begin{tabular}{c|c}
\hline Parity & Rate \\
\hline 1 & $33 \cdot 4$ \\
2 & $22 \cdot 0$ \\
3 & $21 \cdot 8$ \\
4 & $21 \cdot 6$ \\
5 & $26 \cdot 5$ \\
6 & $31 \cdot 7$ \\
7 & $34 \cdot 3$ \\
8 & $34 \cdot 7$ \\
9 & $45 \cdot 5$ \\
$10+$ & $58 \cdot 2$ \\
\hline All Parities & $27 \cdot 2$ \\
\hline
\end{tabular}

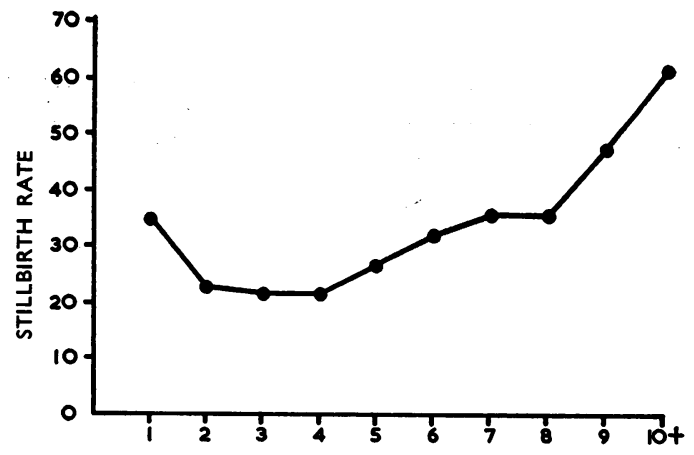

PARITY

Fig. 2.-Stillbirth rate, by parity.

It has always been found difficult to disentangle the effects of these two influences upon the stillbirth rate, because with every successive confinement the mother's age is inevitably higher. Table V shows the Bombay rates by both age and parity. It can be seen that the effect of parity holds for each of the individual maternal age groups, with high rates in

TABLE V

STILLBIRTH RATES PER 1,000 TOTAL BIRTHS BY PARITY AND MATERNAL AGE, BOMBAY, 1957

\begin{tabular}{c|c|c|c|c}
\hline \multirow{2}{*}{ Parity } & \multicolumn{3}{|c}{ Maternal Age (yrs) } \\
\cline { 2 - 4 } & Under 25 & $25-29$ & $30-34$ & $35+$ \\
\hline 2, 3, and 4 & 31 & 41 & 61 & 49 \\
5,6, and 7 & 21 & 20 & 26 & 38 \\
$8+$ & 67 & 29 & 31 & 31 \\
& & 54 & 45 & 41 \\
\hline
\end{tabular}

Note: Ratios based on less than twenty stillbirths are shown in italics. 
the first birth, lowest rates in the second, third, and fourth, and thereafter a rising rate. On the other hand, the effect of maternal age is not consistent or equally pronounced in each parity group. Up to the fifth birth there is a general rise with age. For the fifth, sixth, and seventh births there is little difference with age and later births show a trend in the opposite direction. These findings are in general agreement with those found in other countries, where the influence of parity has been seen to be rather greater than that of maternal age.

\section{Sex Ratio of Stillbirths}

It has been established that conditions conducive to foetal death (with the exception of certain foetal defects) affect male conceptions to a greater extent than female. The sex ratio of live births was 105 in Bombay in 1957, and that of stillbirths 114 .

If, therefore, the incidence of stillbirths varies with parity, these variations should be reflected in corresponding variations in the sex ratio of the stillborn. Table VI shows that the sex ratio, which is high for first births, is least for third births and thereafter rises again. The figures for subsequent parities are too small for any firm conclusions to be drawn.

TABLE VI

SEX RATIO OF STILLBIRTHS, BY PARITY, BOMBAY, 1957

\begin{tabular}{c|c}
\hline Parity & Sex Ratio \\
\hline 1 & $1 \cdot 28$ \\
2 & $1 \cdot 13$ \\
3 & 1.05 \\
4 & 1.12 \\
5 & 1.08 \\
6 & 1.08 \\
7 & 1.28 \\
8 & 1.00 \\
9 & $1 \cdot 11$ \\
$10+$ & 1.42 \\
\hline All Parities & $1 \cdot 14$ \\
\hline
\end{tabular}

The sex ratio is analysed by maternal age in Table VII; it is high in the youngest age group, then falls, and then rises steeply in the oldest age group of 40 years and over.

\section{SUMmaRY}

(1) The Health Department of the Bombay Municipal Corporation recorded 84,910 live and 2,378
TABLE VII

SEX RATIO OF STILLBIRTHS, BY MATERNAL AGE, BOMBAY, 195

\begin{tabular}{c|c}
\hline Maternal Age (yrs) & Sex Ratio \\
\hline $15-19$ & $1 \cdot 23$ \\
$20-24$ & 1.07 \\
$25-29$ & 1.14 \\
$30-34$ & 1.02 \\
$35-39$ & 1.07 \\
40 and Over & 1.64 \\
\hline All Ages & 1.14 \\
\hline
\end{tabular}

stillbirths in 1957 , a stillbirth rate of $27 \cdot 2$ per 1,000 total births. If additional data from the death certificates are included, the rate is 32.6 per thousand total births.

(2) The stillbirth rate was high in the maternal age group 15 to 19 years, then fell, then rose again in the 30-34 age group, and continued to rise thereafter.

(3) The stillbirth rate was high for the first parity, then fell, then rose again at the fifth parity, and continued to rise thereafter.

(4) The sex ratio of the stillborn was 114 and of the live born 105. Among the stillborn it was highest for the maternal age groups and parities in which the incidence of stillbirth was highest.

I am deeply grateful to Prof. F. A. E. Crew whose encouragement and constructive criticism stimulated the preparation of this paper. I am indebted to the Executive Health Officer of the Bombay Municipal Corporation for permission to examine records, to Dr. D. V. Parulekar for making these records easily accessible, and to Dr. K. K. Soman for help in abstracting the data. My thanks are due to Dr. V. N. Panse of the Department of Preventive and Social Medicine for his advice and encouragement and to Mr. J. R. Rele for help in analysing the data.

\section{REFERENCES}

Municipal Commissioner for Greater Bombay (1958). "Administrative Report for the year 1957-58. Vol. II: Annual Report of the Executive Health Officer for 1957". Municipal Printing Press, Bombay.

United Nations Demographic Yearbook for the year

1957 (Ninth Issue). Statistical Office of the United Nations, Department of Economic and Social Affairs, New York. 